\title{
The 4th Annual Scientific Conference for Senior Registrars in Psychiatry*
}

\author{
David CASTLE, Honorary Secretary, CTC
}

Evidently Dublin is the venue to choose if you want your meeting to be well attended. Thus, despite pouring rain which temporarily closed the road to the airport, around 90 senior registrars gathered at Trinity College for the 4th Annual Residential Meeting in June.

An Open Forum chaired by the officers of the Collegiate Trainees' Committee (CTC) provided an opportunity for a discussion of the role of the CTC, as well as the implications for psychiatric trainees of the Calman Report on higher medical training. There was a general feeling that the Report had not really addressed crucial issues such as the paucity of senior registrar and consultant posts, and that many trainees remained in training positions for many years more because of a lack of posts to which to move, rather than any training requirements. The other "set piece" event was the formal dinner, held in the grandeur of Trinity. Professor Anthony Clare was witty and entertaining as after-dinner speaker. He was also provocative, detailing the origins of the Association for Psychiatrists in Training (APIT), which was an organisation outside the College, having been established largely because of opposition to the MRCPsych exam which was being introduced at the time. He encouraged members of the

*Held in Dublin, 10-12 June 1993.

present-day Collegiate Trainees' Committee (firmly a committee within the College) continually to question how trainees' interests can best be served, and to continue to challenge the establishment in this regard. The evening closed to a rendition of songs by Professor Patricia Casey, ably accompanied by a couple of Irish senior registrars, leaving us wondering whether assessment of singing ability is a usual part of the selection process for higher psychiatric trainees across the Irish Sea.

The format for the bulk of the meeting was smallgroup workshops, covering, inter alia, media and presentation skills, clinical audit, research methodology, writing scientific papers, management of aggression, witness skills, management, your first day as a consultant, and the impact of the NHS and community care changes on psychiatric practice. The breadth of topics covered by the workshops makes it impossible to provide details. Suffice it to say that there was something to suit all those attending the meeting, and that the attendance and enthusiasm shown in Dublin assure me that the senior registrars residential meetings will continue to provide a most useful venue for the acquisition of skills and knowledge aimed at enhancing prospects of consultant posts for senior registrars.

The 1994 conference will be held at the University of York from 14 to 16 April.

\section{Defeat Depression Action Week}

\section{3-11 March 1994}

\author{
Aims \\ * to raise awareness about depression \\ * to reduce the stigma associated with it \\ * to give advice on seeking help
}

There will be a two mile fun run in Hyde Park, London, as part of the Defeat Depression Action Week. This will start at 11 a.m. on Sunday, 6 March.
The entry fee is $£ 3$ and the total amount received in entry fees will be matched by a commercial company and all proceeds will be donated to the Defeat Depression Campaign.

To round off the Defeat Depression Action Week there will be a gala dinner dance at the Cumberland Hotel, London on Saturday, 12 March. Tickets will be $£ 25.00$.

If you are interested in either of these two events please contact Christine Gear on 0712352351. 